\title{
Tendencies of economic development of Pacific territories of Russia and their integration into Asia- Pacific region
}

\author{
Maxim Saltykov, Evgeniia Rubinshtein, Anastasia Bessonova, Elena Stenkina \\ Department of Finance and Credit \\ Far Eastern Federal University \\ Vladivostok, Russia \\ saltykov_ma@mail.ru
}

\begin{abstract}
The paper analyzes the investment and socioeconomic efficiency of projects and activities implemented within the overall strategy of integrating the Far Eastern territories of the Russian Federation into the economic space of the AsiaPacific region. The purpose of the work is to express the planned and actually achieved indicators, defined in the state program of socio-economic development of the Far Eastern Federal District, as well as to analyze the set of implemented economic mechanisms for attracting investors from East and South-East Asia. In the presented study, the example of Primorsky Territory reveals the trends of social and economic development in the context of the implementation of public investments within the framework of the program for Far Eastern Federal District development and the subprogram "Development of Vladivostok as a center for international cooperation in the Asia-Pacific region". The study shows that investment in the economy of the Far Eastern Federal District in the amount of 691 billion rubles, including 212 billion rubles in the framework of the subprogram for the preparation for the APEC summit for the period 20082013, did not have the expected impact on the main socioeconomic indicators of the region. The presented analysis reveals the previously formed tendencies of the inertial development of the region.
\end{abstract}

Key words-Regional development, state investments and programs, social and economic efficiency, projects, Far East, integration into the APR, APEC, APR, investments

\section{INTRODUCTION}

Since 2008, the Government of Russia has begun to pay special attention to the development of the Far East as a territory that is a platform for Russia's economic integration into the economic and political system of the Asia-Pacific region.

The theoretical basis for the reforms being implemented is the methodological base and international practice of forming industrial clusters of production location, theory of multiplicative effects in the economy, theoretical concepts of competitiveness and regional industrial clusters [1,2,3].

The approved state program "Economic and Social Development of the Far East and the Baikal Region for the Period until 2018" (hereinafter referred to as the Program) with the Subprogram "Development of the City of Vladivostok as a Center for International Cooperation in the Asia-Pacific Region" testifies to the intention of the Government of the Russian Federation to develop the Far East as Territory with a great economic potential.

The program included a complex of investment projects and the formation of several industrial clusters: transportlogistical, fishery, petrochemical. The total amount of funding for the program, including this subprogram for 2008-2013, was set at 691,995.3 million rubles (including 284,156.6 million rubles under the sub-program); the actual financing of the subprogram amounted to 212,366 million rubles [4].

To meet these challenges, in recent years, certain new mechanisms for the development of the territories of the Far Eastern Federal District and Primorsky Krai have been implemented:

- The Ministry for the Development of the Far East and the Far East Development Foundation were established.

- Federal laws were developed and approved on the Territories of advanced social and economic development (TASED), which determine the special conditions for investors and the implementation of entrepreneurial and other activities.

- The project "Free Port of Vladivostok" and the Far East Hectare project are being implemented.

- The Investment Agency of Primorsky territory was created.

- The Game Zone attracts tourists from the northern provinces of the People Republic of China.

- The Concept for the formation of transport corridors, named as Primorye 1, Primorye 2, has been developed, aimed at modernizing the infrastructure of traffic flows, creating an international corridor for the transport of goods between Europe and the countries of East Asia,

- A project has been developed to create a fisheries cluster, which is a supplier of fish resources to the APR countries, primarily the PRC and Japan. In the Primorsky Territory now, TASED "Mikhailovsky" and "Nadezhdinsky" have been 
established with a total volume of budget and private financing of about 197 billion rubles.

Mechanisms of financial support of business are created by subsidies, including those aimed at compensation of the expenses connected with payment of leasing payments under contracts of financial rent. Also there are subsidies for the business units connected with development and introduction of innovative production, and also for small-sized and medium-sized business units, which produce and sale goods and services for export.

Granting subsidies is possible to those businesses, which have the following:

1) registration on territories of Primorsky Krai of more than 1 year;

2) no debts on payment of taxes and other obligatory payments;

3) do not belong to the categories to which subsidies do not extend.

Seven hundreds of business units will get the state financial support according to the subprogram "Development of small- and medium-sized business in Primorsky Krai". It is scheduled to spend 383 million rubles in total on subsidies for 2017 [4].

According to the Federal law of July 13, 2015, No. 212-FZ "About the Free Port of Vladivostok", the residents of the Free Port are subject to tax benefits, namely the lowered tax rates.

It should be noted that tax holidays extend not to all individual entrepreneurs and not to all branches of small- and medium-sized business. Tax holidays extend on scientific, social and production spheres. It is explained by the need of development of the "weak" and "lagging behind" branches.

As a result of the implementation of the activities of the Program (taking into account the implementation of the subprogram "Development of Vladivostok as a center for international cooperation in the Asia-Pacific region" and projects proposed for funding from the Investment Fund of the Russian Federation), it was planned to achieve the following indicators:

- creation of jobs in the amount of 69,900;

- 2.6-time increase in gross regional product;

- increase in the volume of shipped products by 2.3 times;

- increase in the volume of investments in fixed assets due to all sources of financing by 3.5 times;

- increase in the number of economically active population by 1.1 times;

- reduction in the unemployment rate by 1.7 percents.

It was planned that this would stimulate investment processes in the most competitive segments of the local economy.

In 2008, the Law of Primorsky Krai "On the Strategy of Social and Economic Development of Primorsky Krai until
2025" was approved. The law identified a number of investment projects in the region, with most of these projects aimed at financing the fuel and energy industry, transport, communications [5].

The main objectives of this strategy were: the formation of Vladivostok as a major political, economic and cultural center in the Asia-Pacific region; enhancing the competitiveness of the international transport system of Primorsky Krai in the eastern region; and the development of the industrial and productive sector. The law defined several development scenarios, as well as criteria for assessing efficiency: the gross regional product, the population size, the unemployment rate, the average supply of the population with residential space, the number of foreign tourists, etc.

In 2013, the Investment strategy of Primorsky Krai for the period till 2018 was approved. This strategy consists of 10 main objectives. The planned indicators for achievement of goals on formation of the effective system of attraction of investments and support of investment projects, creation of the most comfortable conditions for start-up and business in the territory of Primorsky Krai are given below:

- Growth of the investments with respect to GRP of Primorsky Krai: in 2015 - not less than $25 \%$, in 2018 - $27 \%$ or more.

- Growth of GRP of Primorsky Krai in 2018 (in \% in previous year in the comparable prices) - not less than $104,7 \%$.

- Investments into fixed capital in 2018 have to make up not less than 540 billion rub.

- Growth rate of direct foreign investments in 2018 has to make in $103.1 \%$ or more [5].

During 2000, mechanisms of formation of territorially production clusters, which appear at certain "points" of industrial and economic growth of the territory, were widely discussed. For development of clusters in 2012, the program of subsidizing pilot innovative clusters was launched. In 2013, 13 clusters received 1,3 billion rubles of subsidies, in 2014, 2,5 billion rubles were distributed between 25 clusters. One of the Far East clusters is a cluster in aircraft industry and shipbuilding. It was also included in the program (Khabarovsky Krai).

Primorsky Krai is a region in which the economic agents connected to the sea are important for its economy. Therefore, in 2013, extensive discussion had occurred about the concept of creation of a fishery cluster. Its implementation cost beforehand was estimated by experts at 39 billion rubles. Nomura Research Institute (NRI) has developed the project for fishery clusters in Primorsky Krai. It was done for the purpose of attraction of foreign technologies and investments. By now, the project has not received real embodiment and it is at a discussion stage.

\section{ANALYSIS}

To assess the effectiveness and extent of implementation of planned activities, the authors will analyze the main economic indicators of Primorsky Krai, designated as targets in the program: GRP, investments in fixed assets, foreign investment, employment indicators for the period before and after the implementation of the state program. Analysis of 
GRP showed that since 2005, this indicator has had a continuous growth trend (Table 1).

TABLE I. ANALYSIS OF THE GRP DYNAMICS IN PRIMORSKY KRAI FOR THE PERIOD OF 2005-2016

\begin{tabular}{|l|r|r|r|r|r|r|r|}
\hline \multicolumn{1}{|c|}{ Index } & $\mathbf{2 0 1 0}$ & $\mathbf{2 0 1 1}$ & $\mathbf{2 0 1 2}$ & $\mathbf{2 0 1 3}$ & $\mathbf{2 0 1 4}$ & $\mathbf{2 0 1 5}$ & $\mathbf{2 0 1 6}$ \\
\hline $\begin{array}{l}\text { GRP. billion } \\
\text { rubles }\end{array}$ & 470.7 & 549.7 & 557.5 & 577.5 & 642.4 & 716.7 & 778 \\
\hline $\begin{array}{l}\text { Absolute } \\
\text { growth. } \\
\text { billion } \\
\text { rubles. }\end{array}$ & 101.7 & 79.0 & 7.8 & 20.0 & 64.9 & 74.2 & 61.3 \\
\hline $\begin{array}{l}\text { Rate of } \\
\text { increase. \% }\end{array}$ & 27.56 & 16.79 & 1.41 & 3.58 & 11.25 & 11.55 & 8.56 \\
\hline
\end{tabular}

However, since 2012, in absolute terms, the highest growth was recorded in 2011 and 2015. However, there is a significant reduction in the growth rate of this indicator. Before 2012, they were at the level of $27.56 \%$ and $16.79 \%$ : after 2012 , they did not exceed $11.55 \%$.

The next important indicator is the dynamics of investments in fixed assets, which is presented in Fig. 1.

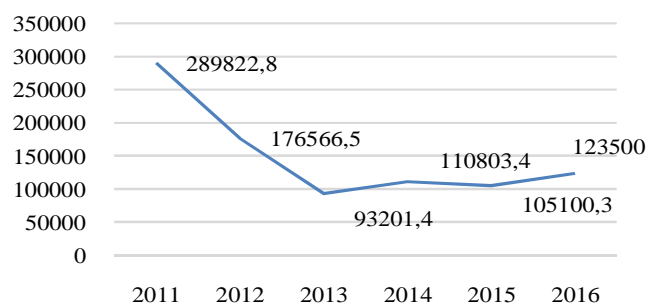

Fig. 1. Dynamics of investment in fixed assets in Primorsky Territory, million rubles

Investments in fixed assets have multidirectional dynamics. In 2011-2013, their amount significantly decreased. Then in 2014, and after a tendency to grow, it continues until 2016. To date, the volume of investments in fixed assets has not reached the level of 2011, but compared to 2013, it grew by $32.5 \%$ [6].

There is a growing trend in the inflow of foreign investment. But foreign investment in the main share is represented in the form of loans - $98 \%$, contributions to fixed assets and securities of regional issuers have share of only $2 \%$ [7].

The dynamics of foreign investment, expressed in US dollars, is also multidirectional. Until 2010, the indicator decreased to a level of $\$ 114.3$ million, but after that, it had a steady growth over five years of more than 10 times - up to 188,999.4 million US dollars [8].

In 2016, Japan, Germany, the Republic of Korea and China were the main investing countries in the region's economy. The share of these countries in the total amount of accumulated foreign investment is about $80 \%$ (Figure 2). The bulk of foreign investment is presented in the form of foreign credits and loans.

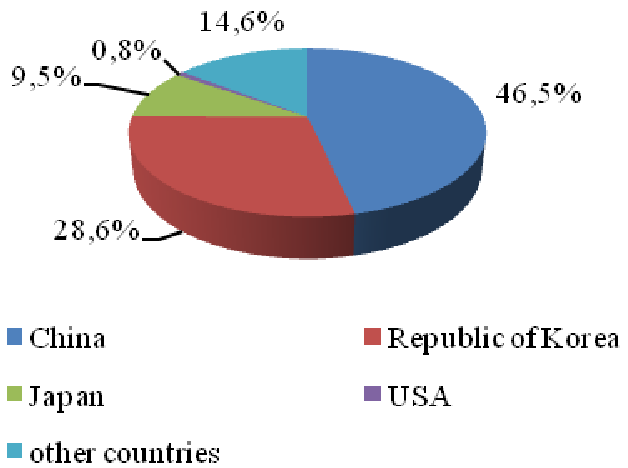

Fig. 2. Foreign investment in the economy of Primorsky Krai, million USD

Indicators of foreign trade decrease. According to the Far East customs office, in 2016, the turnover of foreign trade has decreased by $21 \%$ relatively the same index in 2015 . There was a depreciation of a foreign trade turnover both on export, and on import. Export in 2016, relatively the export in 2015 was reduced by $30 \%$ and has made 2370 million rubles, that is 331,24 million rubles less than it was predicted. A decrease of this indicator is associated with a decrease of sales of oil and oil products abroad 2,6 times. The projected import for 2016 was 9328.5 million rubles. But in fact, in 2016, this figure was 3,211.7 million rubles. A large drop in imports was $52.1 \%$ in $2014-2015$, during the crisis due to the adoption of restrictive measures of political and economic content. The rate of decline in imports in 2016 was $13 \%$ [8].

The main trading partner for both export and import operations is China. The share of the Republic of Korea and Japan are significant too. Thus, one can state that the foreign trade relations of Primorsky Krai are built with the nearest countries of Asia (Figure 3).

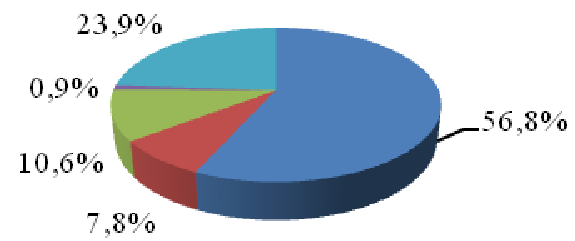

\begin{tabular}{|c|c|}
\hline China & Republic of Korea \\
\hline Japan & USA \\
\hline
\end{tabular}

Fig. 3. The main trade partners in import of Primorsky Krai in 2016

The analysis of tendencies of development of entrepreneurship in the region showed that the number of enterprises in Primorsky Krai is growing. For the period from 2010 to 2016, the number of medium-sized enterprises increased by $94 \%$, and small - one and a half times (Table 2), [8]. 
TABLE II. ANALYSIS OF THE DYNAMICS OF INDICATORS OF SMALL AND MEDIUM-SIZED BUSINESSES IN PRIMORSKY KRAI FOR THE PERIOD OF 20102015

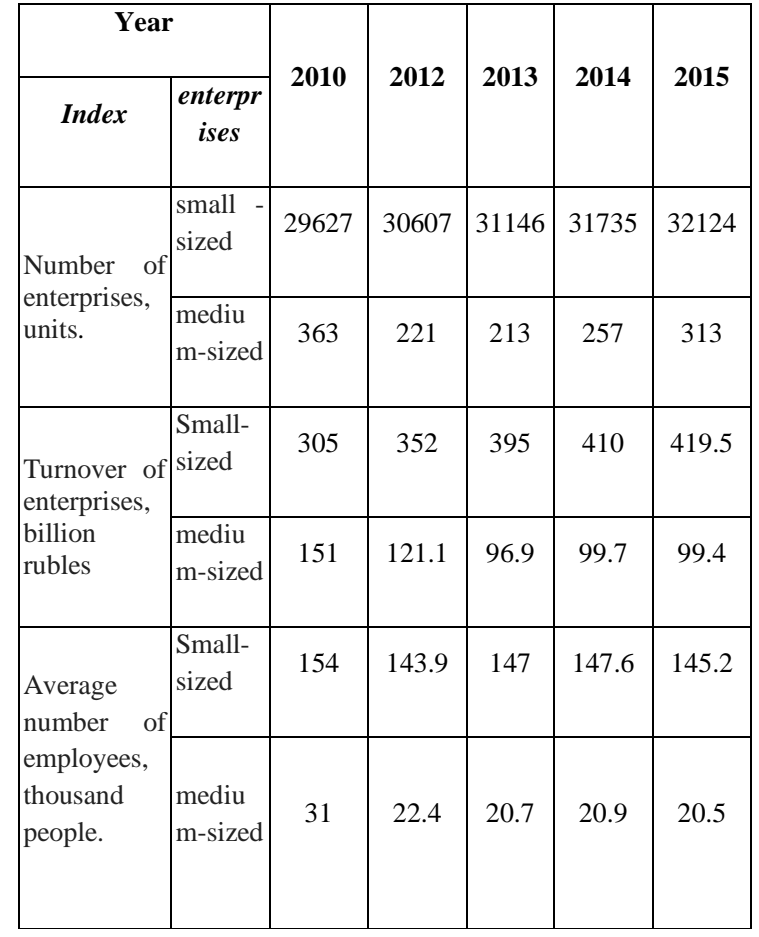

The average number of employees in 2016 compared with the 2010 index, decreased for small and medium-sized enterprises. It should be noted that their main share is in the sphere of trade.

Industry of the territory shows contradictory trends; there is a wave-like decline in the value of fixed assets from 2010 to 2016. In general, the value of fixed assets in the region decreased by $17.32 \%$ during the analyzed period.

In 2015 , the number of enterprises was 4,436 units, and their fixed assets were equal to 408,517 million rubles.

At the same time, there has been a reduction in the number of enterprises, as well as the number of industrial workers; the share of industry in the region's economy is declining (Figure 4).

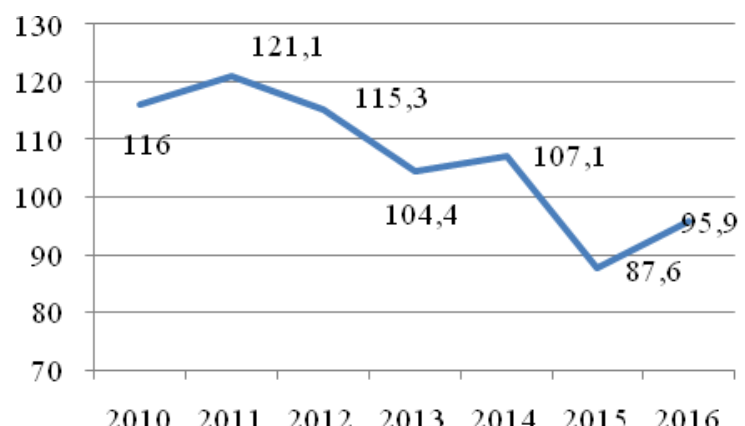

Fig. 4. The index of industrial production, in $\%$ to the previous year
Production growth was achieved in the manufacturing sector: in the production of food products, including beverages; in the production of leather and leather products, in footwear; in metallurgical production and in the production of finished metal products, in the production of vehicles and equipment.

In the structure of industry, there is also a decrease in the share of the fishing industry, although according to the development program of the Far Eastern Federal District, this industry is supposed to have state support in formation of a fishery cluster. Nevertheless, this industry is one of the most integrated in the economic space of the APR.

According to statistics in 2016, as in previous years, there was a significant growth of fish exports. The main commodity output of fish exports remains raw materials, namely fresh and frozen fish with a share of $64 \%$ [8].

One of the problems of the whole region of the Far Eastern Federal District and the Primorsky Territory in particular is the outflow of population and the reduction of labor resources. According to the state program, it was planned to increase the number of economically active population 1.1 times, as well as to reduce the unemployment rate by 1.7 percentage points. The analysis shows that contrary to the planned indicators of the state program, during the period of 2008-2012, the active preparations for the APEC 2012 summit, there was a mixed wave trend: in a number of periods, there was a slight decrease, as well as an increase in the economically active population, employment, unemployment (Table 3), [9].

TABLE III. DYNAMICS OF EMPLOYMENT INDICATORS IN PRIMORSKY KRAI IN 2005 -2016

\begin{tabular}{|l|c|c|c|}
\hline \multicolumn{1}{|c|}{ Index } & $\mathbf{2 0 1 0}$ & $\mathbf{2 0 1 1}$ & $\mathbf{2 0 1 2}$ \\
\hline $\begin{array}{l}\text { Average annual resident } \\
\text { population }\end{array}$ & 1959.4 & 1952 & 1950.5 \\
\hline $\begin{array}{l}\text { Labor resources - total, } \\
\text { thousand people. }\end{array}$ & 1377.6 & 1368.2 & 1355.7 \\
\hline $\begin{array}{l}\text { The level of economically } \\
\text { active population, in \% }\end{array}$ & 67.3 & 67.5 & 68.3 \\
\hline $\begin{array}{l}\text { Level of employment, in } \\
\%\end{array}$ & 60.8 & 62 & 63.6 \\
\hline $\begin{array}{l}\text { Level of unemployment, } \\
\text { in \% }\end{array}$ & 9.7 & 8.1 & 6.9 \\
\hline
\end{tabular}

In general, during the period of the implementation of state programs in $2010-2016$, the decline in the labor force of the region amounted to 30,400 people. The percentage of economically active population is declining and in 2016, it reached the lowest level of $54.39 \%$.

The positive fact is that one can assess the decline in unemployment in the province from $9.7 \%$ in 2010 to $6.0 \%$ in 2016.

The number of scientific papers determined by the PRC, DPRK and some other countries of Southeast Asia as an alternative source of labor resources for the region's economy. 
These countries are the centers for low-skilled labor. But the implementation of the mechanism of attracting labor resources from these regions is currently difficult for a number of administrative problems [10].

"Provision of the population with housing" is actual for the region socio-economic indicator. According to this indicator, the Far Eastern territories occupy the last place among the federal districts. In sociological surveys, unsecured housing and high prices for real estate are determined as the reasons for the outflow of population from Primorye and the regions of the Far Eastern Federal District [11].

Among the additional projects to implement the state program, the pace of housing construction was expected to accelerate and it was logical to assume that additional investment factor effects could arise during the implementation of the state programs. But the data presented in Table 4 show that public investment did not affect the housing conditions of the region's population.

TABLE IV. PROVISION OF HOUSING TO CITIZENS FOR 2006-2015, PRIMORSKY KRAI

\begin{tabular}{|l|c|c|c|c|}
\hline \multicolumn{1}{|c|}{ Index } & $\mathbf{2 0 1 0}$ & $\mathbf{2 0 1 1}$ & $\mathbf{2 0 1 3}$ & $\mathbf{2 0 1 5}$ \\
\hline $\begin{array}{l}\text { Number of families } \\
\text { who received } \\
\text { housing for the year }\end{array}$ & 2647 & 2111 & 2277 & - \\
\hline Growth rate, \% & 142 & 79.8 & 144 & 144 \\
\hline $\begin{array}{l}\text { Housing fund - total } \\
\text { Growth rate, \% }\end{array}$ & 101.3 & 101.5 & 101.1 & 1.01 \\
\hline $\begin{array}{l}\text { Area of housing per } \\
\text { capita, total, sq. m }\end{array}$ & 20.8 & 21.1 & 21.7 & 22.4 \\
\hline $\begin{array}{l}\text { Growth rate, \% } \\
\text { Grecht }\end{array}$ & 103 & 101.4 & 101.4 & 1.01 \\
\hline
\end{tabular}

In recent years, the rate of growth in the housing stock of the Primorsky Krai varies in the range from $0.7-1.5 \%$. In general, it can be noted that infrastructure investments, contrary to the expected multiplicative effects, did not affect the growth rate of the housing stock of the region and other indicators, characterizing the security of the population with housing. To solve this problem and develop the Vladivostok agglomeration, the involvement of Japanese companies and investors is being considered. Japanese companies can be involved in the construction of a fish market, a medical center, modernization of transport infrastructure, construction of lowrise buildings based on Japanese technologies.

The main achievement of the subprogram "Development of the city of Vladivostokak as a center for international cooperation in the Asia-Pacific region" included the establishment of the Far Eastern Federal University as a regional and, in the future, an international educational center.
Currently, one can note the increased ties with foreign institutions of the APR and the growing number of foreign students. The majority of international students are from the PRC, but there are also students from other countries, including Latin American.

In 2016, the list of coastal areas of advanced development was replenished with the shipbuilding TASED "Bolshoy Kamen" and large-scale recruitment of business to the Free Port of Vladivostok. But the real economic effect of the new preferential mechanisms of the region has not been yet received, there are no new jobs, no tax revenues to the budget [12].

At the end of 2016, 63 applications were filed in three coastal TASEDs -"Nadezhdinskaya", "Mikhailovskaya" and "Bolshoi Kamen", of which only 25 were approved, with a total investment of 204 billion rubles.

One hundred and eighty-five requests for the total investment of 255 billion rubles came to the Free Port Vladivostok (FPV) at the end of the year. One hundred and fifteen companies with investments of 152,8 billion rubles have already become residents of FPV.

Newly announced residents of the TASED and FPV along with billions of investments, promise to create tens of thousands of new jobs, but this remains just a loud promise.

Only two residents of the TASED have benefited so far from tax preferences in Primorye.

The mechanisms of "advanced development" in Primorye over the past year have undergone some changes. By the order of the government of the Russian Federation, the boundaries of the "Mikhailovsky" and "Nadezhdinsky" TASED were expanded, and the regime of the Free Port of Vladivostok extended to the Lazovsky District of Primorye.

The key problems of the economy are:

- Decrease in population in the Far Eastern border areas of Russia. The population of the border provinces of China is 100 million people, while in the Far Eastern territories there are just over 6 million people; in the border areas there are just about 2 million people.

- Relatively low socio-economic potential of the Russian territories in comparison with the fast developing countries of the Asia-Pacific region (PRC, Japan, South Korea).

- Low economic, investment and transport integration with the APR countries.

\section{CONCLUSION}

Thus, the main indicators of the strategic objectives of the state program "Economic and social development of the Far East and the Baikal region for the period up to 2018" and the Strategy of social and economic development of Primorsky Krai are in the zone of the inertial scenario. A number of indicators do not reach even inertial values. The GRP indicator 
reached the planned values (716 650 million rubles) by 2015 , but the growth rate of this indicator is slowing down.

Certain goals for integration into the economic space of the APR can be assessed as unreached and promising. The project "Free Port of Vladivostok" is currently similarly at the stage of "potential growth". This circumstance can be explained by the fact that the mechanisms currently being implemented are not yet fully operational; and the effects will appear later. For example, during the second Eastern Economic Forum, more than 50 agreements for 200 billion rubles of investment were signed. A certain share of investors is represented by APR countries and they just plan to create new enterprises on the territory of the region. This is due to the fact that the border area is for foreign investors of one of the attractive regions of the Far East. This is due to several reasons: proximity to the Japanese, Korean and Chinese markets, the availability of railways, transport corridors, ice-free ports, access to the Trans-Siberian Railway and the connection of East Asia regions with Europe.

The population in the province is below the level of the planned indicators of the inertial scenario. The unemployment rate was $6.9 \%$, which exceeds the planned figure of $2.3 \%$. An analysis of real wage growth rates in the period of investment in APEC summit facilities and later periods also show a decrease in real wage growth rates of the population.

An indicative indicator, which is achieved, is the average provision of the population with living space; in 2015, it was 22.1 square meters per person. But the social sphere, the provision of housing, and the quality of life remain the problem zone. This is confirmed by the continuing outflow of the population. If these trends are preserved, the social sphere, the reduction of the population and labor resources will play a more restrictive role in the development of the region's economy, demand more drastic measures than those currently being implemented.

There is a question what factors are associated with the limited achievements of indicators of inertial and target scenarios. Possible factors may include: incorrect planning of state programs, non-execution or partial execution of measures identified in the programs, inconsistency between the implemented measures and the socio-economic situation in the region, the wrongly chosen conceptual base of economic policy.

The analysis shows that the expectations for 2016 are somewhat exaggerated, especially for investments in fixed assets, which in 2016 amounted to 123500 million rubles, which is 215,031.9 million less than expected. On the other hand, agriculture on the contrary gives a positive result, with an increase of $35.16 \%$ in 2016 relative to 2015 , which is by 1,087.1 million rubles more than the forecasted amount.

\section{REFERENCES}

[1] Ernst D., Kim L. Global Production Networks, Knowledge Diffusion, and Local Capability Formation. Research Policy, vol. 31, issue 8-9, pp. 1417-1429, 2002
[2] Cortright, J. Making Sense Of Clusters: Regional Competitiveness And Economic Development, J. Cortright, N.Y., 2006. P. 49.

[3] Porter M.E. Competition in Global Industries: A Conceptual Framework. Competition in Global Industries. Boston: Harvard Business School Press, 1986, pp. 15-60.

[4] Russian Federal target programs. - Federal Program: Subprogram "Development of Vladivostok a sacenter for international cooperationin the Asia-Pacific region". Available at: http://fcp.vpk.ru/cgibin/cis/fcp.cgi/Fcp/ViewFcp/View/2008/261/

[5] Primorsky Krai Law "On the Strategy of Social and Economic Development of Primorsky Krai until 2025". [Electronic resource] URL: http://www.primorsky.ru/authorities/executiveagencies/departments/economics/development/strategy/pk-25.php

[6] E. Rubinshtein, A. Srivastava, "Optimal linear projections for enhancing desired data statistics," in Statistics and Computing, vol. 20 (3), pp.267282, 2010.

[7] A. Nagapetyan, E. Rubinshtein, "Comparison of positive and negative risk indices as a tool for portfolio management," Actual Problems of Economics, vol 7, pp. 142-150, 2016.

[8] The Primorskstat database. Primorskstat. Entrepreneurship. Industry: the contribution of industrial production in the economy of the Primorsky Territory. Available at: http://primstat.gks.ru/wps/wcm/connect/rosstat_ts/primstat/ru/statistics/e nterprises/production/

[9] M. Saltykov, V.Shibanov "The analysis of economical effi-cient investment projects, financed from the federal budget for the development industrial complex Far Eastern Federal District ", Fundamental research, vol. 11, pp. 2705-2712, 2014.

[10] Y. Shmidt, N. Ivashina, N. Ivashina; P. Lobodin, A.Kukhlevsky, "Forecasting of Interregional Migration Flows", Ekonomika regiona Economy of region, vol. 13, pp. 126-136, 2017.

[11] Y. Lezhnina, Socio-economic crisis in Russia: problems of the population and "pockets of concern", Sotsiologicheskie issledovaniya, vol. 10, pp. 54, 2016.

[12] A. Lugovets, V. Rychkova, D. Rychkov, The rationale for the development of united transportation system in Southern Primorye, Marine intellectual technologies, vol. 1 (3), pp.297-302, 2016. 